Revista Brasileira de Agricultura Irrigada v.7, nº 3, p. 201 - 212, 2013

ISSN 1982-7679 (On-line)

Fortaleza, CE, INOVAGRI - http://www.inovagri.org.br

DOI: $10.7127 /$ rbai.v7n300016

Protocolo 016.13 - 04/04/2013 Aprovado em 20/06/2013

\title{
ÁGUA DISPONÍVEL NO SOLO E DOSES DE NITROGÊNIO NO CRESCIMENTO DO GIRASSOL ${ }^{1}$
}

\author{
Doroteu Honório Guedes Filho²; José Amilton Santos Júnior ${ }^{3 *}$; Lúcia Helena Garófalo \\ Chaves $^{4}$; Vinícius Batista Campos ${ }^{5}$; João Tadeu de Lima Oliveira ${ }^{6}$.
}

\section{RESUMO}

A expansão pela qual passa o cultivo do girassol no Brasil, especialmente na região nordeste do país, aumenta a necessidade de informações de manejo que incrementem os índices de produtividade desta cultura. Assim, o objetivo deste trabalho foi estudar o crescimento do girassol variedade EMBRAPA 122-V2000, em função de níveis médios de água disponível (55; 70; 85; e 100\%) em um Neossolo Regolítico eutrófico e da adubação nitrogenada $(0 ; 60$; 80 e $100 \mathrm{~kg} \mathrm{ha}^{-1}$, proveniente da uréia $45 \%$ de N). O delineamento experimental utilizado foi inteiramente casualizado, analisado em esquema fatorial $(4 \mathrm{x} 4)$ com três repetições, totalizando 48 unidades experimentais. Os resultados do experimento foram submetidos à análise de variância, comparando-se por meio de análise de regressão as doses de nitrogênio e os níveis de água disponível no solo. Verificou-se que a interação entre os fatores dose de nitrogênio e níveis médios de água disponível não afetaram o crescimento do girassol; todas as variáveis apresentaram comportamento linear crescente em função do aumento da água disponível no solo, sendo observados os maiores índices de crescimento nas plantas irrigadas com 85 e 100\% da água disponível no solo; a dose de $100 \mathrm{~kg} \mathrm{~N} \mathrm{ha}^{-1}$ proporcionou maiores índices de crescimento.

Palavras-chave: Irrigação, reflectometria no domínio da frequência, Helliantus annuus L.

\section{AVAILABLE SOIL WATER AND LEVELS OF NITROGEN ON GROWTH OF SUNFLOWER}

\footnotetext{
ABSTRACT

The expansion that crosses the cultivation of sunflower in Brazil, especially in the northeast of the country, elevates the need for information that increases the productivity rates of the

*Autor para correspondência

${ }^{1}$ Artigo extraído da Dissertação de Mestrado do primeiro autor, a qual foi apresentada a Coordenação de Pós-Graduação de Engenharia Agrícola da Universidade Federal de Campina Grande - UFCG.

${ }^{2}$ Engenheiro Agrônomo, Doutorando. Departamento de Engenharia Agrícola - UFCG doroteufilho@ hotmail.com

${ }^{3}$ Engenheiro Agrícola, Doutor. Instituto Nacional do Semiárido - INSA/MCTI eng.amiltonjr@ hotmail.com

${ }^{4}$ Engenheira Agrônoma, Doutora. Departamento de Engenharia Agrícola - UFCG lhgarofalo@ hotmail.com

${ }^{5}$ Engenheiro Agrônomo, Doutor. Instituto Federal do Amapá - Campus Laranjal do Jari vinicius.campos@ifpa.edu.br

${ }^{6}$ Eng $^{\circ}$ Agrônomo, Mestre. Secretaria de Estado de Desenvolvimento da Agropecuária e da Pesca, PB tadeuagr@ @otmail.com
} 


\section{ÁGUA DISPONÍVEL NO SOLO E DOSES DE NITROGÊNIO NO CRESCIMENTO DO GIRASSOL}

crop. The objective this work was to study the growth of sunflower variety EMBRAPA 122V2000, according to the average levels of water available $(55,70,85$ and 100\%) in a Entisol eutrophic and nitrogen fertilization $\left(0,60 ; 80\right.$ and $100 \mathrm{~kg} \mathrm{ha}^{-1}$ from urea $\left.45 \% \mathrm{~N}\right)$. The experimental design was completely randomized in a factorial analysis (4 x 4) with three replicates totaling 48 experimental units. The results of the research were subjected to analysis of variance, comparing by means of regression analysis the nitrogen and levels of available soil water. It was found that the interaction between doses of nitrogen and medium levels of available water did not affect the growth of sunflower; all variables increased linearly with the increase of available soil water, being observed the highest rates of growth in plants irrigated with 85 and $100 \%$ of available soil water; the rate of $100 \mathrm{~kg} \mathrm{~N} \mathrm{ha}^{-1}$ provided higher growth rates.

Keywords: Irrigation, frequency domain reflectometry, Helliantus annuus L.

\section{INTRODUÇÃO}

O crescimento das plantas é o aumento irreversível do tamanho, especialmente do material protoplasmático e implica em aumento de peso, do tamanho e no número de células; a sua análise produz conhecimentos de valor prático e informações exatas, referentes ao crescimento e comportamento dos genótipos (Sharma et al., 1993), as quais subsidiam os produtores, de modo que os permite gerenciar situações de escassez e definir, por etapa do crescimento, a aplicação dos recursos disponíveis.

$\mathrm{Na}$ região do semiárido brasileiro, por exemplo, uma das principais limitações à expansão de áreas agrícolas é a escassez de recursos hídricos superficiais de qualidade e disponíveis para a irrigação, fato que reduz a expansão das áreas irrigadas, tornando condição sine qua non a informação exata das necessidades hídricas das culturas, por fase do crescimento, como parâmetro fundamental para o uso racional da água (Santos Júnior et al., 2013) na irrigação.

A compreensão do fator água disponível no solo é uma ferramenta importante na tomada de decisão, uma vez que à medida que a água disponível no solo diminui, a energia a ser utilizada pelas plantas na absorção de água e sais minerais aumenta dado ao potencial matricial. Em regiões áridas e semiáridas com problemas de salinidade o potencial osmótico soma-se ao matricial. Estas informações permitem estabelecer uma relação entre a disponibilidade e o requerimento mínimo de água pelas culturas, favorecendo o gerenciamento dos recursos hídricos disponíveis e a aplicação de volumes diferenciados por estádio fenológico das plantas.

No caso específico da cultura do girassol, por exemplo, Silva et al. (2011) afirmam que o consumo de água varia em função das condições climáticas, porém cita que uma reposição hídrica da ordem de $533,70 \mathrm{~mm}$ (150\% da ECA) proporcionou os maiores potenciais de produção de aquênios.

À medida que o cultivo do girassol ganha importância no Brasil sugere que tecnologias sejam desenvolvidas buscando compreender melhor as suas exigências e assim, adaptálas através do melhoramento genético ou satisfazê-las de acordo com que cada região do país pode oferecer. Pesquisas mostram que se trata de uma cultura que associa alta adaptabilidade a diversas condições edafoclimáticas tendo o seu rendimento pouco influenciado pela latitude, altitude e fotoperíodo (Backes et al., 2008; Porto et al., 2007) ao aproveitamento comercial de todas as suas partes (Neves e Amaral, 2008; Nobre et 


\section{ÁGUA DISPONÍVEL NO SOLO E DOSES DE NITROGÊNIO NO CRESCIMENTO DO GIRASSOL}

al., 2008; Oliveira et al., 2003; Silva et al., 2004; Tomich et al., 2003).

Com relação às exigências nutricionais do girassol, o nitrogênio, após o boro, é o nutriente mais requerido pela cultura e é o que mais limita a produção da mesma, proporcionando redução de até $60 \%$ na produtividade em decorrência da sua deficiência (Biscaro et al., 2008). Pesquisas têm mostrado que tanto o crescimento da planta, como o teor de óleo

\section{MATERIAL E MÉTODOS}

O experimento foi conduzido no período de novembro de 2009 a fevereiro de 2010, em uma casa de vegetação instalada na Unidade Acadêmica de Engenharia Agrícola (UAEAg) da Universidade Federal de Campina Grande UFCG, Campina Grande, PB (latitude $7^{\circ} 12^{\prime} 52^{\prime \prime} \mathrm{S}$; longitude $35^{\circ} 54^{\prime} 24^{\prime \prime} \mathrm{W}$ e altitude média de $550 \mathrm{~m}$ ).

$\mathrm{O}$ delineamento experimental adotado foi inteiramente casualizado, analisado em esquema fatorial $4 \times 4$, com três repetições, totalizando 48 unidades experimentais. Testou-se a combinação de nos aquênios, respondem positivamente aos fertilizantes nitrogenados (Freitas et al., 2012; Oliveira et al., 2012).

Dentro deste contexto, o presente trabalho se propôs a estudar o crescimento do girassol variedade EMBRAPA 122V2000 quando cultivado sob diferentes níveis de água disponível em um Neossolo Regolítico eutrófico e submetido à adubação nitrogenada.

quatro doses de nitrogênio $(0 ; 60 ; 80$ e 100 $\left.\mathrm{kg} \mathrm{ha}^{-1}\right)$, proveniente da uréia ( $45 \%$ de $\mathrm{N}$ ), e quatro níveis médios de água disponível no solo (55; 70; 85 e $100 \%)$.

Cada unidade experimental foi constituída por um vaso plástico de $35 \mathrm{~L}$ de capacidade, preenchido com $32 \mathrm{~kg}$ de material de solo classificado Neossolo Regolítico eutrófico do tipo francoarenoso, proveniente de uma área do distrito de São José da Mata, município de Campina Grande, PB, com as caracterizações físico-químicas (Tabela 1) realizadas segundo metodologia descrita pela Embrapa (1997).

Tabela 1. Característica física e química do solo utilizado no experimento

\begin{tabular}{ll}
\hline Características Físicas & Resultado \\
\hline Areia $\left(\mathrm{g} \mathrm{kg}^{-1}\right)$ & 84,15 \\
Silte $\left(\mathrm{g} \mathrm{kg}^{-1}\right)$ & 8,75 \\
Argila $\left(\mathrm{g} \mathrm{kg}^{-1}\right)$ & 7,1 \\
Textura & Franco - arenoso \\
Densidade Aparente $\left(\mathrm{g} \mathrm{cm}^{-3}\right)$ & 1,40 \\
Densidade Real $\left(\mathrm{g} \mathrm{cm}^{-3}\right)$ & 2,76 \\
Porosidade $(\%)$ & 49,27 \\
Capacidade de Campo (\%) & 7,4 \\
Ponto de murchamento $(\%)$ & 2,8 \\
Água disponível $(\%)$ & 4,6 \\
\hline Características Químicas & \\
pH em água $(1: 2,5)$ & 6,60 \\
CE $\left(\right.$ suspensão solo-água) $\left(\mathrm{dS} \mathrm{m}^{-1}\right)$ & 0,20 \\
Fósforo Assimilável $\left(\mathrm{cmol}_{\mathrm{c}} \mathrm{dm}^{-3}\right)$ & 28,50 \\
Cálcio $\left(\mathrm{cmol}_{\mathrm{c}} \mathrm{dm}^{-3}\right)$ & 2,55 \\
Magnésio $\left(\mathrm{cmol}_{\mathrm{c}} \mathrm{dm}^{-3}\right)$ & 2,23 \\
Sódio $\left(\mathrm{cmol}_{\mathrm{c}} \mathrm{dm}^{-3}\right)$ & 0,06 \\
Potássio $\left(\mathrm{cmol}_{\mathrm{c}} \mathrm{dm}^{-3}\right)$ & 0,28 \\
CTC $\left(\mathrm{cmol}_{\mathrm{c}} \mathrm{dm}^{-3}\right)$ & 5,91 \\
\hline
\end{tabular}




\section{ÁGUA DISPONÍVEL NO SOLO E DOSES DE NITROGÊNIO NO CRESCIMENTO DO GIRASSOL}

$\mathrm{O}$ solo nas unidades experimentais foi adubado com superfosfato triplo $\left(\mathrm{P}_{2} \mathrm{O}_{5}\right)$ e cloreto de potássio $\left(\mathrm{K}_{2} \mathrm{O}\right)$ na dosagem correspondente a $80 \mathrm{~kg} \mathrm{ha}^{-1}$, sendo que todo $\mathrm{P}_{2} \mathrm{O}_{5}$ e $40 \%$ da dose de $\mathrm{K}_{2} \mathrm{O}$, para cada unidade experimental, foram aplicados em fundação; o restante da dose de $\mathrm{K}_{2} \mathrm{O}$ foi aplicado em duas vezes: aos 28 e 52 dias após a semeadura (DAS). As doses de nitrogênio foram aplicadas em cobertura de modo que metade foi incorporada aos 28 DAS e o restante aos 52 DAS. Aos 28 DAS foi adicionado a cada unidade experimental, o correspondente a $2 \mathrm{~kg} \mathrm{ha}^{-1}$ de boro, proveniente de ácido bórico.

A variedade de girassol estudada foi a Embrapa 122-V2000 e o semeio foi realizado diretamente nos vasos utilizandose dez sementes distribuídas e distanciadas de forma equidistante, a uma profundidade média de 0,02 m; aos 20 DAS realizou-se um desbaste visando à obtenção de apenas uma planta por vaso.

O conteúdo de água no solo ao longo do período experimental foi monitorado diariamente, através de uma sonda segmentada DIVINER Reflectometria no Domínio da Frequência (FDR), a qual era inserida no solo através de um tubo de acesso instalado nos vasos com tratamento correspondente a $100 \%$ da água disponível (AD), em três intervalos de profundidade: $0-10 ; 10-20$ e $20-30 \mathrm{~cm}$.

\section{RESULTADOS E DISCUSSÃO}

Os tratamentos com doses de nitrogênio afetaram positivamente o número de folhas apenas aos 60 DAS (Tabela 2) de modo que o comportamento desta variável ajustou-se ao modelo de regressão linear $(\mathrm{p}<0,01)$ (Figura 1A) discordando dos resultados observados por
Os dados eram compilados em planilhas eletrônicas em função da equação da curva de retenção de água no solo e então, utilizando-se funções matemáticas previamente programadas, calculava-se o volume de reposição referente a $100 \%$ da $\mathrm{AD}$; a partir destes resultados, por extrapolação, calculava-se o volume de reposição para os outros níveis de água disponível no solo (55, 70 e $85 \%$ ). As irrigações foram feitas diariamente, sempre às $16 \mathrm{~h}$.

Aos 20; 40; 60 e 80 DAS foram avaliados os parâmetros biológicos indicativos do crescimento das plantas: número de folhas (NF) - foram contabilizadas as folhas com comprimento mínimo de $0,03 \mathrm{~m}$ e fotossinteticamente ativas; diâmetro do caule (DC) mensurado sempre na região do colo da planta, a 0,05 $\mathrm{m}$ do solo; comprimento do caule (CC) - distância entre o colo da planta e a inserção da folha mais nova; e área foliar (AF) - calculada segundo metodologia proposta por Maldaner et al. (2009): $\mathrm{AF}=0,1328 \times \mathrm{C}^{2,5569}$, em que C é o comprimento da nervura central de cada folha da planta.

Os dados foram submetidos à análise de variância com teste $\mathrm{F}(\mathrm{p}<0,01)$ e aplicada à análise de regressão polinomial. Todas as análises foram realizadas utilizando-se o programa estatístico SISVAR-ESAL (Ferreira, 2003).

Biscaro et al. (2008) que estudando a aplicação parcelada de $\mathrm{N}$ em cobertura ( 0 a $80 \mathrm{~kg} \mathrm{ha}^{-1}$ de N) sobre a cultura do girassol em condição de campo, notaram que o número de folhas aumentou em função destas doses em todas as datas de avaliação. 


\section{ÁGUA DISPONÍVEL NO SOLO E DOSES DE NITROGÊNIO NO CRESCIMENTO DO GIRASSOL}

Tabela 2. Resumo da ANOVA para número de folhas do girassol (Helliantus annus L.), variedade EMBRAPA 122-V2000, em diferentes datas, submetido a diferentes níveis de água disponível no solo e doses de nitrogênio.

\begin{tabular}{lllll}
\hline \multirow{2}{*}{ Fonte de variação } & \multirow{2}{*}{ GL } & \multicolumn{3}{l}{ Quadrado médio } \\
\cline { 3 - 5 } & & 20 DAS & 40 DAS & 60 DAS \\
\hline Doses de nitrogênio - N & 3 & $1,19^{\text {ns }}$ & $19,52^{\text {ns }}$ & $99,41^{* *}$ \\
Regressão linear & 1 & - & - & $180,21^{* *}$ \\
Água disponível - AD & 3 & $0,30^{\mathrm{ns}}$ & $34,35^{* *}$ & $3,19^{\mathrm{ns}}$ \\
Regressão linear & 1 & - & $95,00^{* *}$ & - \\
Interação dos fatores - N x AD & 9 & $5,30^{\mathrm{ns}}$ & $12,59^{\mathrm{ns}}$ & $6,00^{\mathrm{ns}}$ \\
Resíduo & 32 & 2,35 & 6,69 & 6,77 \\
\hline CV (\%) & \multicolumn{5}{c}{14,94} & 16,14 & 19,86 \\
,** & significativo a 5\% e 1\%, respectivamente, e ${ }^{\mathrm{ns}}$ não significativo, pelo teste F. GL: Grau de liberdade e CV:
\end{tabular}

O efeito da $\mathrm{AD}$ sobre o número de folhas mostrou-se significativo $(\mathrm{p}<0,01)$ apenas aos 40 DAS, com o comportamento linear crescente (Figura 1B). Os resultados observados nas plantas irrigadas com 85 e $100 \%$ de AD no solo apresentaram maior número de folhas quando comparado com outros tratamentos e comportamento similar, quando comparados entre si, indicando a possibilidade da utilização de $85 \%$ de AD sem perdas para cultura em se tratando do número de folhas. Estes resultados discordam dos obtidos por Göksoy et al. (2004) que após avaliarem 13 tratamentos de irrigação durante três anos, não observaram interferência estatística sobre a variável em questão.

Aos 60 DAS, o aumento das doses de $\mathrm{N}$ ocasionou um incremento de $0,66 \%$ no NF por incremento unitário de $\mathrm{N}\left(\mathrm{kg} \mathrm{ha}^{-}\right.$ ${ }^{1}$ ), sendo estimado, com base na equação

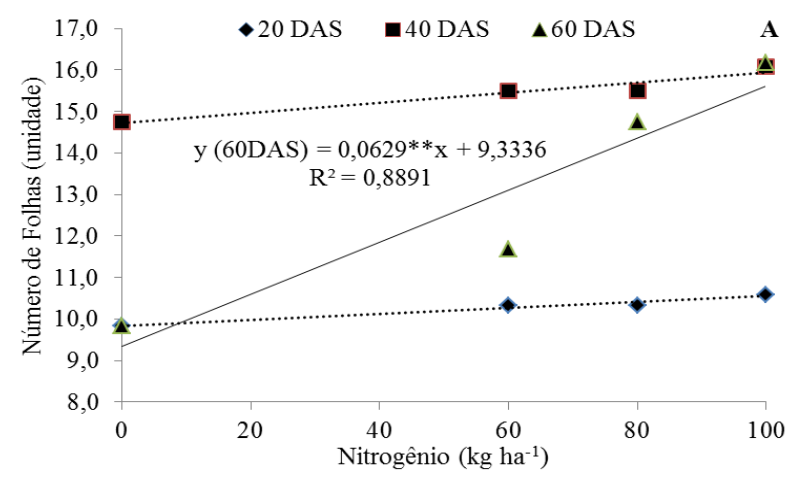

de regressão, que as plantas sob $100 \mathrm{~kg} \mathrm{ha}^{-}$ ${ }^{1}$ de N, produziram 16 folhas (Figura 1), resultado tardio se comparado aos resultados de Prado e Leal (2006), que aos 30 DAS, observaram 16 folhas nas plantas de girassol, variedade Catissol-01, cultivadas em solução nutritiva com o tratamento completo. Esses resultados discordaram em parte dos obtidos por Fagundes et al. (2007), que com doses e fontes de $\mathrm{N}$ na cultura do girassol ornamental, não verificaram resposta destas para o número de folhas em função das fontes.

Considerando-se a evolução do número de folhas ao longo do tempo, as diferentes doses de $\mathrm{N}$ e níveis de $\mathrm{AD}$ do solo, incrementaram o número de folhas até os 40 DAS decrescendo a partir desta data, com exceção da aplicação de $100 \mathrm{~kg}$ ha $^{-1} \mathrm{~N}$ (Figura 1).

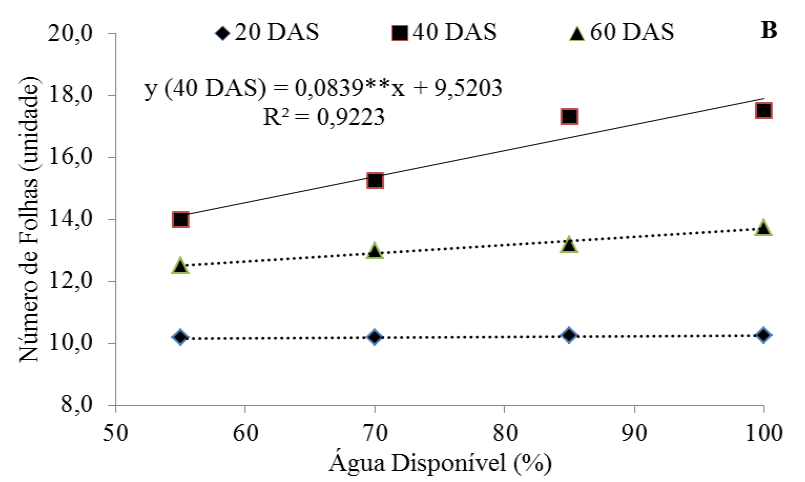

Figura 1. Número de folhas do girassol (Helliantus annus L.), variedade EMBRAPA 122-V2000, (A) em função das doses de nitrogênio em $\mathrm{kg} \mathrm{ha}^{-1} \mathrm{e} \mathrm{da} \mathrm{(B)} \mathrm{porcentagem} \mathrm{da} \mathrm{água} \mathrm{disponível} \mathrm{no} \mathrm{solo.}$ 


\section{ÁGUA DISPONÍVEL NO SOLO E DOSES DE NITROGÊNIO NO CRESCIMENTO DO GIRASSOL}

O diâmetro do caule, em função das doses de $\mathrm{N}$ testadas, foi influenciado aos 60 e 80 DAS (Tabela 3), sendo que uma equação polinomial de segunda ordem descreveu o seu comportamento aos 60 DAS ( $<$ < 0,05) (Figura 2A); aos 80 DAS, o comportamento ajustou-se ao modelo linear $(\mathrm{p}<0,01)$ (Figura 2A). Os valores médios do diâmetro caulinar encontrados aos 60 e 80 DAS, foram em torno de 10,5 e $11,5 \mathrm{~mm}$, respectivamente. Estes valores foram menores que os observados por Prado e Leal (2006) e Ivanoff et al. (2010) que, avaliando o diâmetro caulinar da variedade Catissol-01 e de três cultivares de girassol na Savana de Roraima, observaram valores médios de $15,4 \mathrm{~mm}$ e $12,2 \mathrm{~mm}$, respectivamente. A paralisação no crescimento vegetativo, verificado neste trabalho em torno dos 45 a 55 DAS, ocorreu em função da aceleração do comportamento produtivo que ocorre pelo direcionamento dos fotoassimilados produzidos para outros órgãos (Taiz e Zeiger, 2006), a exemplo das flores e aquênios.

Tabela 3. Resumo da ANOVA para diâmetro caulinar do girassol (Helliantus annus L.), variedade EMBRAPA 122-V2000, em diferentes datas, submetido a diferentes níveis de água disponível no solo e doses de nitrogênio.

\begin{tabular}{|c|c|c|c|c|c|}
\hline \multirow{2}{*}{ Fonte de variação } & \multirow{2}{*}{ GL } & \multicolumn{4}{|c|}{ Quadrado médio } \\
\hline & & 20 DAS & 40 DAS & 60 DAS & 80 DAS \\
\hline Doses de nitrogênio $-\mathrm{N}$ & 3 & $1,30^{\mathrm{ns}}$ & $5,32^{\mathrm{ns}}$ & $12,30 * *$ & $11,80^{* *}$ \\
\hline Regressão linear & 1 & - & - & $18,60 * *$ & $23,02 * *$ \\
\hline Regressão quadrática & 1 & - & - & $13,07 *$ & - \\
\hline Água disponível - AD & 3 & $1,24^{\mathrm{ns}}$ & $9,99 *$ & $12,26^{* *}$ & $14,43 * *$ \\
\hline Regressão linear & 1 & - & $26,27 * *$ & $36,58 * *$ & $42,08 * *$ \\
\hline Interação dos fatores - $\mathrm{N} \times \mathrm{AD}$ & 9 & $1,05^{\mathrm{ns}}$ & $1,65^{\mathrm{ns}}$ & $1,88^{\mathrm{ns}}$ & $2,46^{\mathrm{ns}}$ \\
\hline Resíduo & 32 & 0,51 & 2,27 & 1,86 & 1,70 \\
\hline $\mathrm{CV}(\%)$ & & 10,22 & 15,98 & 13,77 & 12,85 \\
\hline
\end{tabular}

Aos 40; 60 e 80 DAS, os valores de diâmetro caulinar foram afetados pela $\mathrm{AD}$ no solo (Figura 2B) com comportamentos ajustáveis a uma reta $(\mathrm{p}<0,01)$. Observou-se na Figura 2B que os valores do diâmetro caulinar com os níveis de $85 \%$ e $100 \%$ de $\mathrm{AD}$ no solo, foram semelhantes entre si e que estes valores foram crescentes em função das porcentagens de AD no solo, tendo visto o melhor nível de $100 \%$.

A dose $100 \quad \mathrm{~kg} \quad \mathrm{ha}^{-1} \quad \mathrm{~N}$ proporcionou maior influência sobre $\mathrm{O}$ diâmetro caulinar em todas as datas de avaliação (Figura 2A) e as quantidades de AD correspondentes a 85 e $100 \%$ (Figura 2B) apresentaram maiores índices de crescimento quando comparadas com as demais porcentagens, corroborando com Silva et al. (2007) que registraram resposta positiva de lâminas de água tanto para o comprimento do caule quanto para $o$ diâmetro caulinar de dois genótipos de girassol. 
ÁGUA DISPONÍVEL NO SOLO E DOSES DE NITROGÊNIO

NO CRESCIMENTO DO GIRASSOL
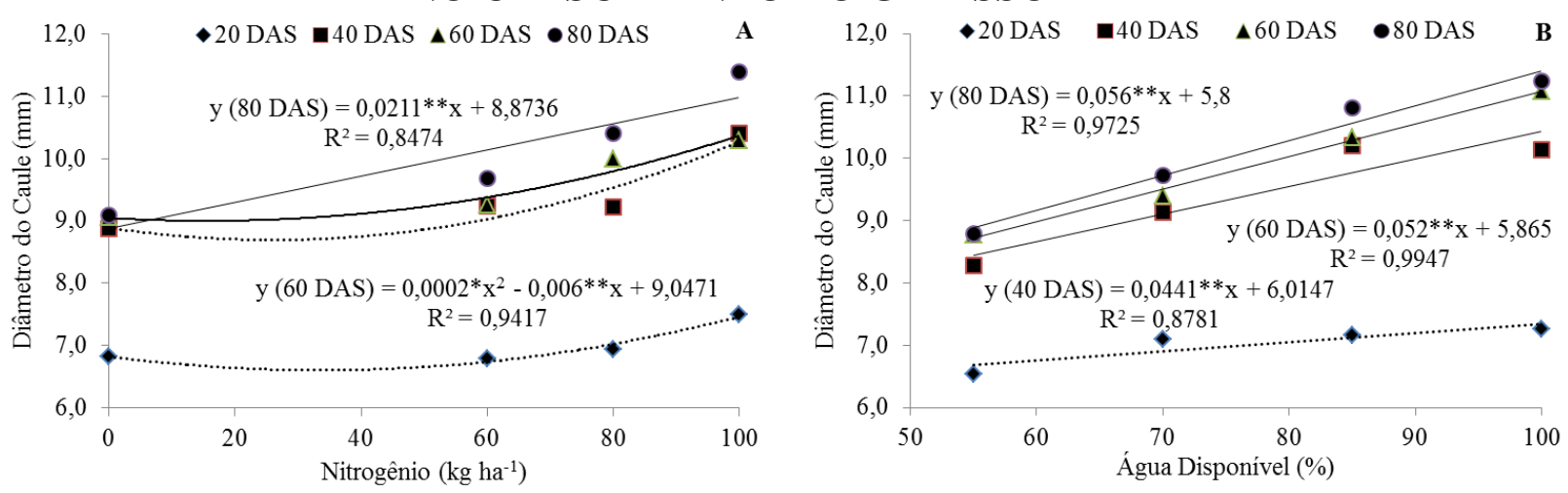

Figura 2. Diâmetro do caule do girassol (Helliantus annus L.), variedade EMBRAPA 122-V2000, (A) em função das doses de nitrogênio em $\mathrm{kg} \mathrm{ha}^{-1} \mathrm{e}$ (B) da água disponível no solo.

Em se tratando do comprimento do caule, as doses de $\mathrm{N}$ não apresentaram efeitos significativos (Tabela 4 e Figura 3A) corroborando com Barni et al. (1995) e Ivanoff et al. (2010) que estudando o crescimento do girassol em resposta aos níveis de adubação, notaram que o girassol não evidencia diferenças no crescimento da planta. Neste caso, resultados divergentes foram encontrado por Fagundes et al. (2007) no desenvolvimento do girassol ornamental, os quais demonstraram que as maiores doses de $\mathrm{N}$ proporcionaram maiores comprimentos de caule.

Os níveis de água disponível no solo afetaram o comprimento do caule aos 40; 60 e 80 DAS; o comportamento das curvas ajustou-se ao modelo de regressão linear ( $\mathrm{p}<0,01$ ), em todos os casos (Tabela 4). Aos 40 DAS entre os níveis de 55 a $100 \%$ de $\mathrm{AD}$, houve um acréscimo no $\mathrm{CC}$ da ordem de $0,15 \mathrm{~m}$; aos 60 DAS houve pouca variação no crescimento do caule, e, aos $80 \mathrm{DAS}$, as variações foram superiores a $0,20 \mathrm{~m}$ (Figura 3B).

Tabela 4. Resumo da ANOVA para comprimento do caule do girassol (Helliantus annus L.), variedade EMBRAPA 122-V2000, em diferentes datas, submetido a diferentes níveis de água disponível no solo e doses de nitrogênio.

\begin{tabular}{lccccc}
\hline \multirow{2}{*}{ Fonte de variação } & \multirow{2}{*}{ GL } & \multicolumn{4}{c}{ Quadrado médio } \\
\cline { 3 - 6 } & & 20 DAS & 40 DAS & 60 DAS & 80 DAS \\
\hline Doses de nitrogênio - N & 3 & $56,86^{\text {ns }}$ & $313,08^{\text {ns }}$ & $102,23^{\text {ns }}$ & $241,55^{\text {ns }}$ \\
Água disponível - AD & 3 & $44,60^{\text {ns }}$ & $650,86^{* *}$ & $1548,29^{* *}$ & $1775,52^{* *}$ \\
Regressão linear & 1 & - & $1949,97^{*}$ & $4467,75^{* *}$ & $4780,23^{* *}$ \\
Interação dos fatores - N x AD & 9 & $15,42^{\text {ns }}$ & $150,80^{\text {ns }}$ & $118,06^{\text {ns }}$ & $206,49^{\text {ns }}$ \\
Resíduo & 32 & 24,55 & 107,33 & 112,75 & 272,83 \\
\hline $\mathrm{CV}(\%)$ & & 12,2 & 13,32 & 10,65 & 16,75 \\
\hline
\end{tabular}

*, ** significativo a 5\% e 1\%, respectivamente, $\mathrm{e}^{\text {ns }}$ não significativo, pelo teste F. GL: Grau de liberdade e CV: coeficiente de variação.

O comportamento da evolução do comprimento do caule, tanto para as doses de $\mathrm{N}$ (Figura 3A) quanto para as porcentagens de AD no solo (Figura 3B) foi similar, entretanto, sob 85 e $100 \%$ de $\mathrm{AD}$ as plantas apresentaram melhor desenvolvimento ao longo do tempo, com variação de cerca de $0,10 \mathrm{~m}$ entre estas. Observou-se também que o comprimento do caule das plantas de girassol foi maior em todas as épocas de cultivo, quando adubadas com $100 \mathrm{~kg} \mathrm{ha}^{-1}$ de $\mathrm{N}$. 


\section{ÁGUA DISPONÍVEL NO SOLO E DOSES DE NITROGÊNIO NO CRESCIMENTO DO GIRASSOL}
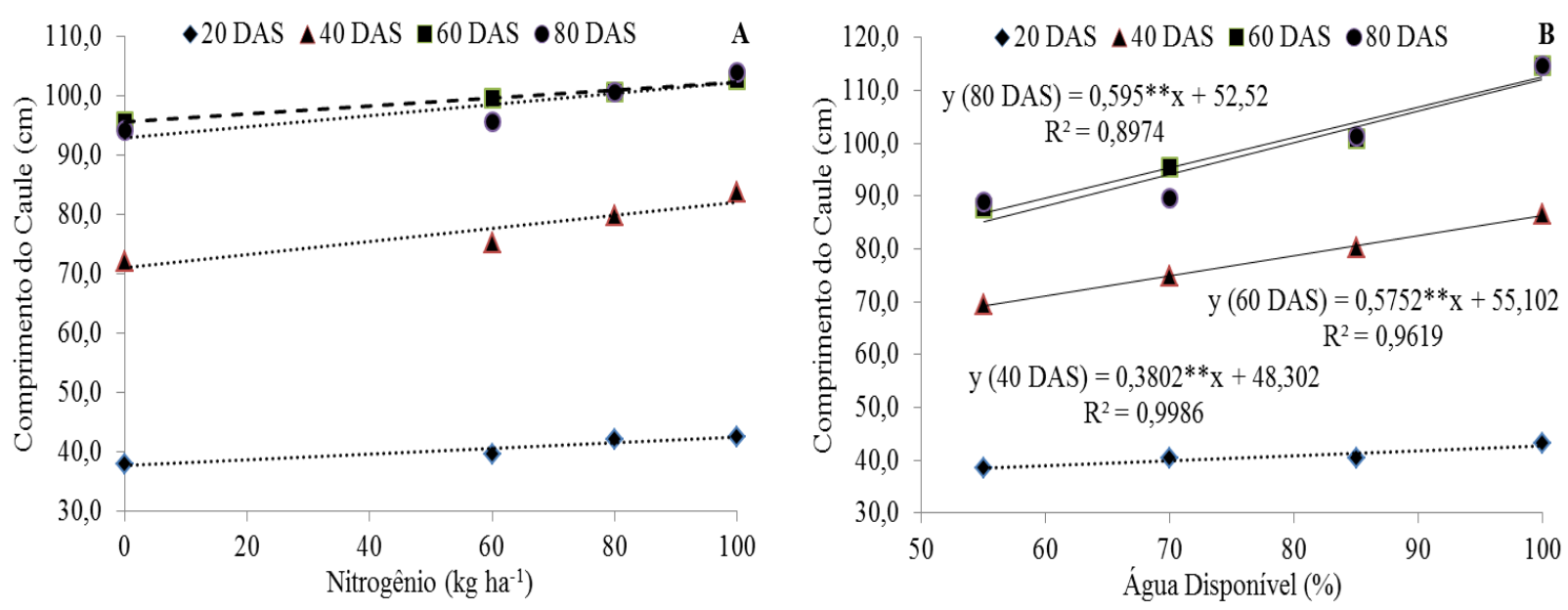

Figura 3. Comprimento do caule do girassol (Helliantus annus L.), variedade EMBRAPA 122V2000, (A) em função das doses de nitrogênio em $\mathrm{kg} \mathrm{ha}^{-1} \mathrm{e}$ (B) da água disponível no solo.

A área foliar foi um parâmetro sensível em relação aos tratamentos com o $\mathrm{N}$ uma vez que existe uma estreita relação entre a área foliar e a atividade fotossintética, e consequentemente, o desenvolvimento das plantas. Segundo Malavolta et al. (1997), a presença de N é relacionada com a produção de clorofila, ocasionando, em caso de deficiência deste elemento, modificações nos cloroplastos. A presença de $\mathrm{N}$ atua na divisão celular e, consequentemente, no crescimento das plantas.

Da mesma forma que as doses de $\mathrm{N}$, o fator água disponível no solo atuou de forma significativa na área foliar das plantas, aos 40 e 60 DAS (Tabela 5). O comportamento dos resultados da AF está explícito na Figura 4A e 4B para as doses de $\mathrm{N}$ e para o fator $\mathrm{AD}$, aos $40 \mathrm{DAS}$ e aos 60 DAS, respectivamente.

O tamanho das folhas é relacionado ao suprimento de $\mathrm{N}$ para elongação e/ou divisão celular (Garcez Neto et al., 2002), fato que justifica o aumento da área foliar a medida que as doses de $\mathrm{N}$ são incrementadas. Os resultados da área foliar do presente trabalho, aos 40 e 60 DAS, foram significativos em função das doses de $\mathrm{N}$ e AD no solo, corroborando com Soriano et al. (2004), mostrando que as plantas de girassol em condições irrigadas tem maiores valores de área foliar do que as plantas com limitação de água.

As plantas cultivadas sob a maior dose de $\mathrm{N}$ aplicada (100 $\mathrm{kg} \mathrm{ha}^{-1}$ de $\mathrm{N}$ ) apresentaram maior área foliar resultando em valores da ordem de 1269,25 $\mathrm{cm}^{2}$ aos 40 DAS e $1489,25 \mathrm{~cm}^{2}$ aos 60 DAS. Entretanto esses valores encontram-se inferiores aos $2100 \mathrm{~cm}^{2}$ e $2500 \mathrm{~cm}^{2}$ obtidos por Prado e Leal (2006) e Fagundes et al. (2007), respectivamente.

Em se tratando do comportamento da área foliar ao longo do tempo (Figura 4A) a dose $100 \mathrm{~kg} \mathrm{ha}^{-1}$ de $\mathrm{N}$ foi a única que apresentou crescimento a partir dos 40 DAS, sendo que a partir desta data todas as outras doses testadas apresentaram decréscimo. 


\section{ÁGUA DISPONÍVEL NO SOLO E DOSES DE NITROGÊNIO NO CRESCIMENTO DO GIRASSOL}

Tabela 5. Resumo da ANOVA para área foliar aos 40 e 60 DAS do girassol (Helliantus annus L.), variedade EMBRAPA 122-V2000, em diferentes datas, submetido a diferentes níveis de água disponível no solo e doses de nitrogênio.

\begin{tabular}{lccc}
\hline \multirow{2}{*}{ Fonte de variação } & \multirow{2}{*}{ GL } & \multicolumn{2}{c}{ Quadrado médio } \\
\cline { 3 - 4 } & & AF40 DAS $^{1}$ & AF60 DAS $^{1}$ \\
\hline Doses de nitrogênio - N & 3 & $118,91^{*}$ & $1096,87^{* *}$ \\
Regressão linear & 1 & $160,67^{* *}$ & $2025,86^{* *}$ \\
Regressão quadrática & 1 & - & $112,94^{* *}$ \\
Desvio de regressão & 1 & - & $1151,83^{* *}$ \\
Água disponível - AD & 3 & $243,57^{* *}$ & $260,17^{* *}$ \\
Regressão linear & 1 & $55,84^{* *}$ & $712,53^{* *}$ \\
Interação dos fatores - N x AD & 9 & $15,15^{\text {ns }}$ & $50,03^{\text {ns }}$ \\
Resíduo & 32 & 35,91 & 19,14 \\
\hline CV(\%) & & 19,59 & 16,60 \\
\hline
\end{tabular}

*, ** significativo a 5\% e 1\%, respectivamente, $\mathrm{e}^{\mathrm{ns}}$ não significativo, pelo teste F. GL: Grau de liberdade e CV: coeficiente de variação. ${ }^{1}$ Variáveis transformadas $(X+0,5)^{0,5}$.

Quando observadas em função do fator água disponível no solo (Figura 4B) todos os níveis apresentaram decréscimo a partir dos 40 DAS, entretanto as melhores tendências foram obtidas por 85 e $100 \%$ de AD.
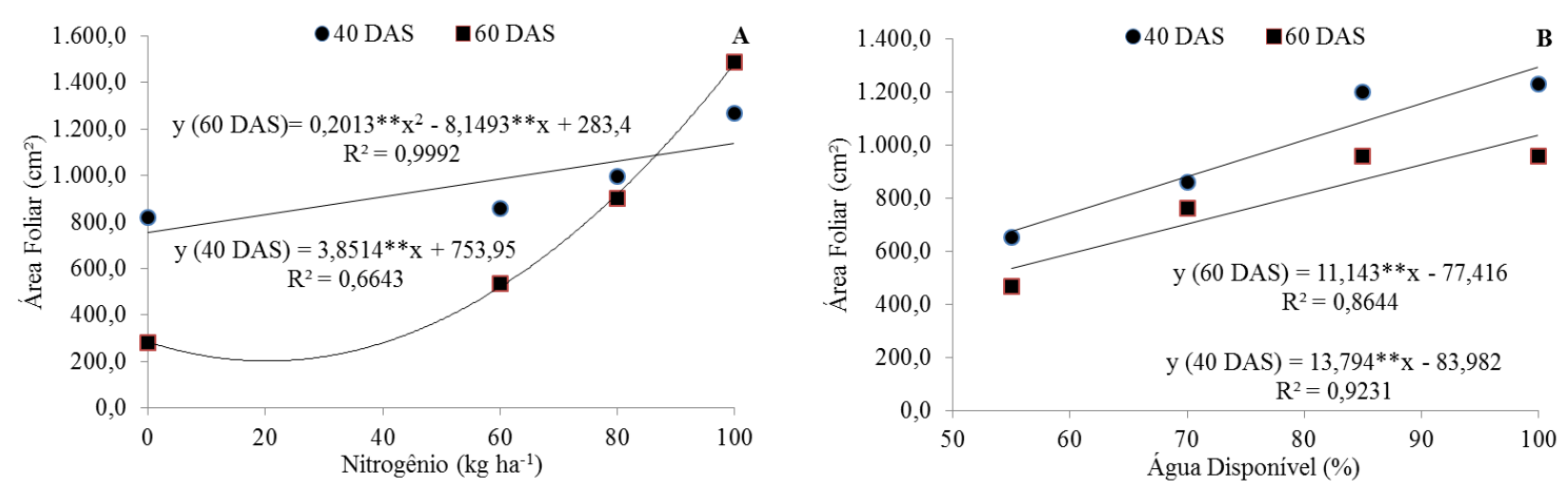

Figura 4. Área foliar do girassol (Helliantus annus L.), variedade EMBRAPA 122-V2000, (A) em função das doses de nitrogênio em $\mathrm{kg} \mathrm{ha}^{-1} \mathrm{e}(\mathrm{B})$ da água disponível no solo.

\section{CONCLUSÕES}

A interação entre os fatores água disponível no solo e doses de nitrogênio não afetou o crescimento do girassol;

Rev. Bras. Agric. Irrigada v. 7, nº 3, p. 201 - 212
O crescimento do girassol apresentou comportamento linear crescente em função do incremento da água disponível no solo, sendo observados os 


\section{ÁGUA DISPONÍVEL NO SOLO E DOSES DE NITROGÊNIO NO CRESCIMENTO DO GIRASSOL}

maiores índices de crescimento nas plantas irrigadas com 85 e $100 \%$ de água disponível no solo;

\section{REFERÊNCIAS}

BACKES, L. R.; SOUZA, A. M.; BALBINOT JUNIOR, A. A.; GALLOTTI, G. J. M.; BAVARESCO, A. Desempenho de cultivares de girassol em duas épocas de plantio de safrinha no planalto norte catarinense. Scientia Agraria, v.9, n.1, p.41-48, 2008.

BARNI, N. A.; BERLATO, M. A.; SANTOS, A. O. Análise de crescimento do girassol em resposta a cultivares, níveis de adubação e épocas de semeadura. Pesquisa Agropecuária Gaucha, v. 1, p. 167-184, 1995.

BISCARO, G. A.; MACHADO, J. R.; TOSTA, M. DA S.; MENDONÇA, V.; SORATTO, R. P.; CARVALHO, L. A. Adubação nitrogenada em cobertura no girassol irrigado nas condições de Cassilândia-MS. Ciência e Agrotecnologia, v. 32, n. 05, p. 13661373, 2008.

\section{EMPRESA BRASILEIRA DE PESQUISA AGROPECUÁRIA EMBRAPA. Centro Nacional de Pesquisa de Solos. Manual de métodos de análise de solo. 2ed. Rio de Janeiro, 1997, 212p.}

FAGUNDES, J.D.; SANTIAGO, G.; MELLO, A.M.; BELLÉ, R.A.; STRECK, N.A. Crescimento, desenvolvimento e retardamento da senescência foliar em girassol de vaso: fontes e doses. Ciência Rural, v. 37, n. 4, p. 987-993, 2007.

FERREIRA, D. F. SISVAR 4.6 Sistema de análises estatísticas. Lavras: UFLA, 2003. 32 p.
A dose de $100 \quad \mathrm{~kg} \quad \mathrm{~N} \quad \mathrm{ha}^{-1}$ proporciona maiores índices de crescimento.

FREITAS, C. A. S.; SILVA, A. R. A. da; BEZERRA, F. M. L.; ANDRADE, R. R.

de; MOTA, F. S. B.; AQUINO, B. F. de. Crescimento da cultura do girassol irrigado com diferentes tipos de água e adubação nitrogenada. Revista Brasileira de Engenharia Agrícola e Ambiental, v.16, n.10, p.1031-1039, 2012.

GARCEZ NETO, A. F.; NASCIMENTO Jr, D.; REGAZZI, A. J. Respostas morfogênicas e estruturais de Panicum maximum cv. Mombaça sob diferentes níveis de adubação nitrogenada e alturas de corte. Revista Brasileira de Zootecnia, v. 31, n. 5, p. 1890-1900, 2002.

GÖKSOY, A. T.; DEMIR, A. O.; TURAN, Z. M.; DAGÜSTÜ, N. Responses of sunflower (Helianthus annuus L.) to full and limited irrigation at different growth stages. Field Crops Research, v. 87, n. 2-3, p. 167-178, 2004.

IVANOFF, M. E. A.; UCHÔA, S. C. P.; ALVES, J. M. A.; SMIDERLE, O. J.; SEDYAMA, T. Formas de aplicação de nitrogênio em três cultivares de girassol na savana de Roraima. Revista Ciência Agronômica, v. 41, n. 3, p. 319-325, 2010.

MALAVOLTA, E.; VITTI, G.C.; OLIVEIRA, S.A. Avaliação do estado nutricional das plantas: princípios $\mathrm{e}$ aplicações. 2.ed. Piracicaba: Potafos, 1997. 319p. 


\section{ÁGUA DISPONÍVEL NO SOLO E DOSES DE NITROGÊNIO NO CRESCIMENTO DO GIRASSOL}

MALDANER, I. C.; HELDWEIN, A. B.; LOOSE, L. H. ; LUCAS, D. D. P.; GUSE, F. I.; BORTOLUZZI, M. P. Modelos de determinação não-destrutiva da área foliar em girassol. Ciência Rural, v. 39, n.5, p. 1356-1361, 2009.

NEVES, M. F.; AMARAL, R. O. Flores oportunidades e desafios. Revista Agro Analysis, v. 27, p. 30-31, 2008.

NOBRE， R. G.; ANDRADE， L. O.; SOARES, F. A. L.; GHEYI, H. R.; FIGUEIREDO, G. R. G.; SILVA, L. A. Vigor do girassol (Helianthus annuus L.) sob diferentes qualidades de água. Revista Educação Agrícola Superior, v. 23, n.1, p. 58-60, 2008.

OLIVEIRA, J. T. de L.; CHAVES, L. H. G.; CAMPOS, V. B.; SANTOS JÚNIOR, J. A.; GUEDES FILHO, D. H. Fitomassa de girassol cultivado sob adubação nitrogenada e níveis de água disponível no solo. Revista Brasileira de Agricultura Irrigada, v. 6, n. 1, p.23-32, 2012.

OLIVEIRA, M. C.; MARTINS, F. F.; ALMEIDA, C. V.; MOURA, C. D. Efeito da inclusão de bagaço de girassol na ração sobre o desempenho e rendimento de carcaça de frangos de corte. Revista Portuguesa Zootecnia, v.10, n. 2, p. 107116, 2003.

PORTO, W.S.; CARVALHO, C.G.P.; PINTO, R.J.B. Adaptabilidade e estabilidade como critérios para seleção de genótipos de girassol. Pesquisa Agropecuária Brasileira, v. 42, p. 491499, 2007.

PRADO, R. M.; LEAL, R. M. Desordens nutricionais por deficiência em girassol var. Catissol-01. Pesquisa Agropecuária Tropical, v. 36, n. 3, p. 187-193, 2006.
SANTOS JÚNIOR, J. A.; BARROS JÚNIOR, G.; SANTOS, J. K. L.; BRITO, E. T. F. S. Uso racional da água: ações interdisciplinares em escola rural do semiárido brasileiro. Ambi-Agua, v. 8, n. 1, p. 263-271, 2013. http://dx.doi.org/10.4136/ambi-agua.1075

SHARMA, B. D.; KAUL, H. N.; SINGH, $M$. Growth analysis of potato varieties in autumn in subtropical conditions. New Botanist, v. 20, n. 54, p. 55-64, 1993.

SILVA, A. R. A. da.; BEZERRA, F. M. L.; SOUSA, C. C. M. de; PEREIRA FILHO, J. V.; FREITAS, C. A. S. Desempenho de cultivares de girassol sob diferentes lâminas de irrigação no Vale do Curu, CE. Revista Ciência Agronômica, v. 42, n. 1, p. 57-64, 2011.

SILVA, B. O.; LEITE, L. A.; FERREIRA, M. I. C.; FONSECA, L. M.; REIS, R. B. Silagens de girassol e de milho em dietas de vacas leiteiras: produção e composição do leite. Arquivo Brasileiro de Medicina Veterinária e Zootecnia, v.56, n. 6, p.750-756, 2004.

SILVA, M. L. O. E.; FARIAS, M. A.; MORAIS, A. R.; ANDRADE, G. P.; LIMA, E. M. C. Crescimento e produtividade do girassol cultivado na entressafra com diferentes lâminas de água. Revista Brasileira de Engenharia Agrícola e Ambiental, v. 11, n. 5, p. 482488, 2007.

SORIANO, M. A.; ORGAZ, F.; VILLALOBOS, F. J.; FERERES, E. Efficiency of water use of early plantings in sunflower. Europe Journal Agronomic, n. 21, p. 465-476, 2004.

TAIZ, L.; ZEIGER, E. Fisiologia Vegetal. 4 ed. Porto Alegre: Artmed, 2006, 719p. 


\section{ÁGUA DISPONÍVEL NO SOLO E DOSES DE NITROGÊNIO NO CRESCIMENTO DO GIRASSOL}

TOMICH, T. R. et al. Potencial forrageiro de cultivares de girassol produzidos na safrinha para ensilagem. Arquivo
Brasileiro de Medicina Veterinária e Zootecnia, v.55, n. 6, p. 756-762, 2003. 